\title{
Prebiotic inulin: Useful dietary adjuncts to manipulate the livestock gut microflora
}

\author{
A.K. Samanta, Natasha Jayapal, S. Senani, A.P. Kolte, Manpal Sridhar \\ National Institute of Animal Nutrition and Physiology, Adugodi, Hosur Road, Bangalore, India.
}

Submitted: March 28, 2011; Approved: July 2, 2012.

\begin{abstract}
In recent years, there has been a growing appreciation on the relevance of gastrointestinal microflora in both ruminants and non-ruminants owing to revelation of their role in several physiological functions including digestion, nutrient utilization, pathogen exclusion, gastrointestinal development, immunity system, gut gene expression and quality of animal products. The ban imposed on the use of antibiotics and hormones in feed has compelled animal researchers in finding an alternative which could overcome the issues of conventional feed additives. Though the concept of prebiotic was evolved keeping in mind the gastrointestinal flora of human beings, presently animal researchers are exploring the efficiency of prebiotic (inulin) for modulating the gut ecosystem of both ruminants and non-ruminants. It was revealed that prebiotic inulin is found to exhibit desirable changes in the gut of non-ruminants like poultry, swine, rabbit etc for augmenting gut health and improvement of product quality. Similarly, in ruminants the prebiotic reduces rumen ammonia nitrogen, methane production, increase microbial protein synthesis and live weight gains in calves. Unlike other feed additives, prebiotic exhibits its effect in multipronged ways for overall increase in the performances of the animals. In coming days, it is expected that prebiotics could be the part of diets in both ruminants and non-ruminants for enabling modulation of gut microflora vis a vis animals productivity in ecological ways.
\end{abstract}

Key words: prebiotic, inulin, mechanism of action, livestock.

\section{Introduction}

The world has witnessed immense development in nutritional science during the last century which gave birth to the concept of balanced diet following identification of the essential nutrients for supporting growth, development, production in addition to the prevention of deficiency symptoms. Research efforts during the past decades resulted in the development of feeding standards for different species, breeds, and production levels across the world to maximize productivity as well as to ensure higher returns from livestock enterprises. During the $20^{\text {th }}$ century, one of the major contributions of nutritional science is the concept of the "balanced diet" which may be defined (applicable to ruminants) as "an appropriate mixture of roughage and concentrate in the form of mash or block capable to fulfill the requirements of nutrients needed to support maintenance, growth and production of animals". In the case of non-ruminants it may be considered as "an appropriate mixture of feed ingredients that essentially fulfills the nutrient requirements for carrying out cell function without exhibiting deficiency disorders". At the turn of the $21^{\text {st }}$ century, the 'balanced ration' and the 'nutrient requirements' remained the key concepts. However, with changing lifestyle in the present century, the consumer demands and requirement has drastically changed. Recently, prebiotics has been introduced as a new concept under functional food science owing to concern over residues of antibiotic or hormones, consumer awareness and safety features. Keeping in view the above circumstances, presently animal nutrition research draws more attention on feed safety, quality, designer animal products, healthy animal products, ecological treatment for digestive disorder and organic animal production. It seems prebiotics specifically inulin has potential to address these issues and capable to bring out the desired effects on animal performances. 
The addition of prebiotics in the diets of animals is a relatively recent endeavor and preliminary studies are very encouraging. Although the effect of most functional foods target only one or a limited number of functions, the prebiotics target a range of different physiological functions starting from bowel performance and colonic microflora activities to mineral absorption, lipid homeostasis and immunity (Gibson et al., 2004; Samanta et al., 2011).

\section{Gastrointestinal microflora}

Based on the occurrence of microbial habitat in the gastrointestinal tract (Figure 1), domestic animals may be classified into two categories viz.; mono gut fermentor non-ruminants (namely poultry, swine, horse, rabbit, donkey etc) and twine gut fermentors - ruminants and pseudoruminants (namely cattle, buffalo, sheep, goat, mithun, camel etc). The gastrointestinal tract of ruminant is featured with the provision of two microbial habitats i.e. foregut (rumen, reticulum and omasum) and hindgut (caecum). On the other hand non-ruminants are featured with the presence of single microbial habitats i.e. hindgut only. The presence of foregut with enormous capacity to house diverse categories of microflora provide the edge to ruminant animals over the non-ruminants for consumption and dependence on lignocellulosic biomass to obtain their energy requirements through volatile fatty acids (viz.; acetate, propionate, butyrate etc) generated from the degradation and anaerobic fermentation of fibrous materials. The single fermentation site i.e. at the hindgut of non-ruminant animal permeates partial dependence over the volatile fatty acids for energy requirements. It is estimated that rumen fluids contain (number $/ \mathrm{mL}) 10^{10}$ to $10^{12}$ bacteria, $10^{4}$ to $10^{6}$ protozoa, $10^{8}$ to $10^{9}$ archea, $10^{2}$ to $10^{4}$ fungi in addition to yeast, phage etc. (Hobson et al., 1988; Hungate, 1966; Samanta et al., 2003).

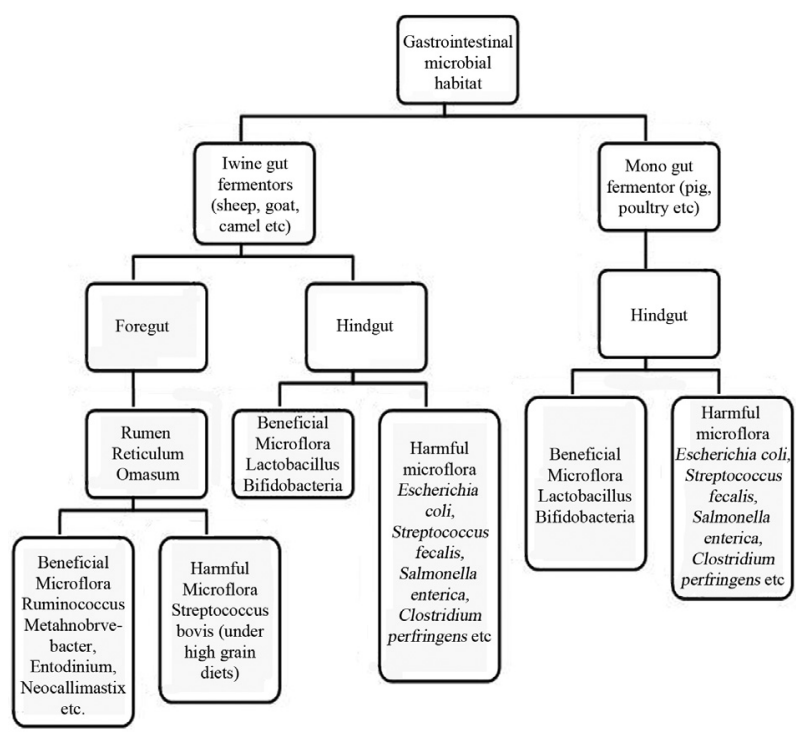

Figure 1 - Classification of livestock based on microbial habitats.
Similarly, the hindgut of non-ruminants is also act as habitat for millions of bacteria, archaea, fungi and yeasts. By virtue of unique environment available in terms of nutrients, $\mathrm{pH}$, interaction, temperature, crosstalk in the gastrointestinal tract, both beneficial and harmful microflora get niche for their growth and multiplication. Inability to explain certain features following completion of human genome project enforces researchers to relook into the gut microflora for better understanding and answering the unresolved issues. In this regard, gut microflora are considered to evolve along with the human evolution and humans have been proposed to be "metaorganisms"; consisting of 10 -fold greater numbers of bacteria than animal cells (Gill et al., 2006; Neish, 2009; Xu et al., 2007). The human "metaorganisms" include approximately $10^{14}$ prokaryotic organism having a biomass of $>1 \mathrm{~kg}$ and often considered as hidden organ having the capacity equivalent to liver. The complete development of gastrointestinal tract and immunological system takes place only after the establishment of gut microflora thus signifying the absence of signals within human genome to carry out complete development of either gastrointestinal tract or immune system. From the above analogy, one could guess the contribution and significance of microflora inhabiting at foregut and hindgut of ruminants and hindgut of non-ruminants.

\section{Classification of gut microflora}

The classical cultivation based methods adopted by researchers grouped the gut microflora based on strain, shape, biochemical features, nutrient utilization etc and nowadays it is presumed that only 10 to $20 \%$ of microflora from the habitat could be cultivable by following the standard cultivation techniques (Harmsen et al., 2000). To address the issues of uncultivable microflora, presently gut ecologists study the microflora through 16S rRNA based protocols which take care of both cultivable and uncultivable microflora. Ignoring the specific substrate utilization pattern (cellulose, hemicellulose, protein, lipid, pectin etc) or biochemical features, microflora of the gastrointestinal tract could be broadly grouped into two main categories namely pathogenic or harmful or detrimental microflora and health promoting or friendly or beneficial or pathogen suppressive microflora. The class of pathogenic bacteria includes Escherichia coli, Streptococcus faecalis, Salmonella enterica, Clostridium perfringens etc. Lactobacillus and Bifidobacteria inhabited in the gastrointestinal tract are presumed to be the major members of beneficial or health promoting class. The significance of prebiotic consumption arises from their ability to selectively stimulate the growth and multiplication of indigenous Bifidobacteria and Lactobacilli in the hindgut, which in turn suppresses the activity of putrefactive or harmful bacteria for reducing the concentration of toxic fermentation products in the gastrointestinal tract (Samanta et al., 2007, 2010; Tomomatsu, 1994). 


\section{Harmful fermentation metabolites}

In non-ruminants (poultry, swine, horse, dog), the large intestine especially the caecum is the primary site for millions of microflora belonging to diverse groups. In the ruminants (cattle, buffalo, sheep, goat), the ingested materials are exposed to extensive action by diverse group of microflora and their enormous array of hydrolyzing enzymes before they are subjected to utilization by animal's own gastric or pancreatic enzymes. The gastrointestinal motility permeates the delivery of digested materials at large intestine and hence once again the ingested materials are subjected to the action of microbial enzymes. As a result, several biochemical reactions take place at the site of microbial habitats i.e. either at rumen or caecum, resulting in the generation of enormous metabolites possessing beneficial or harmful action.

A wide number of toxic metabolites are generated following microbial fermentation of feed at large intestine. The major toxic metabolites of hindgut include ammonia, amines, nitrosamines, phenols, cresols, indole, skatole, estrogens, aglycone, secondary bile acid etc. The adverse affects of these metabolites are hepatotoxicity (ammonia, amines etc.), carcinogenicity (nitrosamines, phenols, cresols etc), mutagenic (aglycone) etc. Microflora involved in the formation of various toxic metabolites are Escherichia coli and Clostridium spp. (ammonia, amines, nitrosamines, phenol, indole, aglycone, secondary bile acids), Bacteroides spp., Streptococcus fecalis (nitrosamines, aglycones, secondary bile acids), Proteus spp. (ammonia, amines and indoles) (Tomomatsu , 1994). Primary enzyme involved in the formation of carcinogens from procarcinogens in the gastrointestinal tracts is azoreductase. Highest order of azoreductase enzyme activity is noticed in Clostridium spp., followed by Eubacterium spp. and Peptostreptococcus spp. and no activity is detected in Bifidobacteria spp. (Saito et al., 1992). In addition to the formation of toxic metabolites or secretion of enzymes involved in production of harmful products, several gastrointestinal disorders are also noticed due to breakdown of gut microbial homeostasis (Moxley and Duhamal, 1999; Pope and Cherry, 2000).

\section{Prebiotics}

Prebiotics are a group of bio-molecules grouped together by virtue of their capability to promote the growth and multiplication of specific beneficial gut microflora. Ban on the use of antibiotics and hormones as feed additives, consumer awareness, strict quality control measures are the driving factors for intense research and development in the areas of functional food, especially the prebiotic oligosaccharides. Although the concept of functional foods has been introduced a long time ago by great ancient Greek philosopher Hippocrates "Let food be thy medicine and medicine be thy food", scientific evidences started to sup- port the above principle only recently through the application of prebiotics for modulating the gut microflora. The term "Prebiotics" came into light only recently and is coined by Gibson and Roberfroid (1995), who exchanged "pro" to "pre", which means "before" or "for" (Aida et al., 2009). Prebiotics may be defined as "non-digestible food ingredients that beneficially affect the host by selectively stimulating the growth and or activity of one or a limited number of bacteria in the colon". As it matches with certain aspects of dietary fiber, the updated version of prebiotics encompasses "selectively fermented ingredients that allow specific changes, both in the composition and/ or activity in the gastrointestinal microflora that confers benefits upon host well being and health" (Gibson et al., 2004). Recently, FAO (2007) defined the prebiotic as "A non-viable food component that confers a health benefit on the host associated with modulation of the microbes". Although the effect of most functional foods targets only one or a limited number of functions, but the prebiotic targets a range of different physiological functions including better gut health, higher mineral absorption, lowering of cholesterol, immune stimulation and pathogen exclusion (Raschka and Deniel, 2005; Roberfroid, 2007). Therefore, the prebiotics are characterized by their non-digestibility at gastric levels, selective stimulation to the beneficial gut microflora, biological origin and obviously without any residue problems.

\section{Evolution of prebiotic concept}

Basically the novel concept of prebiotic was forwarded keeping in view its application for human health and well being (Gibson and Roberfroid, 1995). Since last few decades there has been growing interest between gastrointestinal microflora and different physiological functions of human beings with much attention being thrust on the prebiotic carbohydrates which are not digested or utilized by the enzymes secreted by the eukaryotic own glandular system; but are completely accessible to the selective group of gastrointestinal microbial communities i.e. beneficial gut microflora. Carbohydrates are stored in the form of fructan in more than 36,000 species available in the world (Hendry, 1987). Owing to the improper preservation of plant materials by early ancestors, the physical proof for consumption of crops rich in prebiotics is virtually nonexistent (Leach et al., 2006). However, it could definitely be presumed that today's prebiotics either inulin or oligofructose were consumed by the Pliocene and Pleistocene ancestors a million years ago through the diverse plant materials (Laden and Wrangham, 2005; Leach, 2007). Gradually the prebiotics rich foodstuffs became part of the human diets in some areas in earlier days and it is thought that the quantity of prebiotic consumption might exceed today's prebiotic level that is consumed by the modern population (Van Loo et al., 1995). Off late, the scientific definition for prebiotics was forwarded during mid nineties of previous century (Gibson and Roberfroid, 1995) keeping in view the 
significance of utilizing plant derived compounds for augmenting gut health and functionality. Because of immense importance, prebiotic is presently thought to be a forerunner amongst several nutraceuticals for application towards routine maintenance of health as well as for ecological treatment of disorders pertaining to gastrointestinal tract.

\section{Characteristics of prebiotics}

Originally, the concept of prebiotics aroused after keeping in mind the gut ecology of human beings. Therefore, criteria set to qualify a biomolecule as prebiotic may not be the same as it was proposed by earlier researchers. Hence criteria for a compound to become a prebiotic in livestock are as follows (Samanta et al., 2007):

- Indigestibility by animal's own gastric or pancreatic enzymes.

- Selectively utilized by so called beneficial gut microflora (exception several rumen bacteria ferments prebiotics).

- Plant origin or produced by microbial enzymes.

- Non-absorption from the epithelial surface of gastrointestinal tract.

- Protects structural and functional integrity while passing through either acidic or alkaline $\mathrm{pH}$ of gastrointestinal tract.

- Exhibit its potentiality even at minute concentration.

- Remains intact while undergoing physical action of digestion process i.e. mastication, chewing, mixing with several fluids etc.

- Presence of chemicals bonds that is inaccessible to harmful gut microflora.

- No residue problems in livestock or their products.

- Non-carcinogenic.

- Its fermentation should not lead to generate metabolite of toxic nature.

- Easy to mix with other feed ingredients or micronutrient mixture.

\section{Inulin type prebiotics}

Despite the fact that the original concept of prebiotic was forwarded after keeping in mind the structure and function of inulin on human gastrointestinal tract but with the passage of time, a number of prebiotic has came into light and are on the way to establish their niche in the competitive market of functional foods (Samanta et al., 2012). Nevertheless inulin occupies top position in the list of prebiotics because of their availability from a wide resources with minimum cost involvement and includes a group of biomolecules viz.; inulin, oligofructose and fructooligosaccharides. Inulin and its different forms are present in a wide variety of plants as natural storage carbohydrates.

It was first discovered as a "peculiar substance" by German scientist Rose in the year 1804 from the hot water extract of roots of plants (Inula helenium) belonged to Compositae family. Later on, the term "inulin" was coined by Thomson in 1818. Chemically it is fructan made up of fructose units linked by $\beta$ - 2, 1 linkage of which terminal sugar is obviously glucose. Inulin is represented by general formula $\mathrm{GF}_{\mathrm{n}}$, while oligofructose by $\mathrm{F}_{\mathrm{m}}$ and/or $\mathrm{GF}_{\mathrm{n}}$; ' $\mathrm{G}$ ' is glucosyl unit, ' $F$ ' is fructosyl unit, ' $n$ ' is the number of fructose units linked to terminal glucose units and ' $\mathrm{m}$ ' is the number of fructose units linked to each other in the carbohydrate chain (Franck, 2000; Niness, 1999). In case of inulin, ' $n$ ' is greater than 2 and less than 60 . Oligofructose, obtained by partial hydrolysis of inulin can be a mixture of both $\mathrm{GF}_{\mathrm{n}}$ and Fm molecules with DP varying from 2 to 7 or 8 to10 depending on the products' brand (Franck, 2000). Nonetheless only $\mathrm{GF}_{\mathrm{n}}$ type oligofructose could be produced from inulin by enzymatic hydrolysis or by transfructosylation of sucrose molecule in the presence of fructosyl transferase (Sangeetha et al., 2005). First elongation of sucrose with one fructose molecule leads to generation of fructooligosaccharides termed as 1-kestose and further elongation leads to production of 1-nystose and so on (Samanta et al., 2010). The degree of polymerization (DP) refers to the number of repeating units (fructose) present in the prebiotic inulin or oligofructose and depends upon plant source, growing stages, climatic conditions, post harvest processing etc. Inulin may also contain minor amounts of $F_{m}$ fructans $\left(F_{2}\right)$, although GFn fructans with DP from 2 to 60 are predominant.

Inulin is storage polysaccharides that encompasses all linear fructan (Roberfroid, 2007) and is widely distributed in nature. Spectrum of inulin occurrence is reported in more than 36,000 plant species (Carpita et al., 1989; Van Loo et al., 1995) and the list include roots of chicory (15-20\%), burdock (3.5 -4\%), salsify (4-11\%), yacon $(3-19 \%)$, murnong $(8-13 \%)$, bulbs of onion (2-6\%), garlic (9-16\%), leek (3-10\%), camas (12-22\%), tubers of Jerusalem artichoke (16-20\%), leaves of dandelion (12-15\%), artichoke (3-10\%) in addition to a number of cereals and fruits. Presently most of the inulin is produced from roots of chicory in which chain length ranges from 2 to 60 , with an average degree of polymerization 10 . Oligofructose is made by 2 to 8 molecules of fructose units, terminally linked with a glucose moiety. The presence of $\beta-2,1-$ osidic bonds either inulin or oligofructose make the prebiotic indigestible by mammalian enzymes (Gibson et al., 2004).

\section{Effect of inulin in livestock}

During the last one and a half decades there has been growing interest amongst the diverse field of researchers to ensure multidimensional application of prebiotics for well being of human society. As a result it finds its place for augmenting gut health and functionality, regularization of fecal output in older individuals, sweetener for diabetic patient, ecological treatment of gastrointestinal disorders especially 
inflammatory bowel disease etc. (Gibson et al., 2004; Saito et al., 1992; Van Loo et al., 1995). Although preliminary studies on prebiotic application in the diets of livestock are encouraging, the quantum of data pertaining to livestock are frugal. In the present review efforts have been made to assemble that sporadic information into meaningful directions.

\section{Swine}

Swine experiences many stressors during their entire life, out of which weaning is most important. During this phase often there is breach in the gut microbial homeostasis as a result of changes in gut microflora composition. Presently the European Union has banned the use of antibiotics in feed and some countries are considering banning it as feed supplements. Under such circumstances, prebiotics either derived from plant or synthesized by microbial enzymes offers to occupy the vacuum of antibiotics for improving the productivity of livestock keeping in mind the demerits of antibiotics applications. Newborn piglets consuming oligofructose exhibited higher number $\left(1.68 \times 10^{10}\right.$ vs. $4.85 \times 10^{9} \mathrm{CFU} / \mathrm{g}$ fecal contents) of Bifidobacteria on $6^{\text {th }}$ day of consumption (Howard et al., 1995). In an effort to see the potentiality of prebiotic inulin on recovery from induced diarrhoea by cholera enterotoxin at the age of $3^{\text {rd }}$ weeks in piglets, the population of lactobacilli was significantly higher in both caecum (9.3 vs. $7.7 \log _{10}$ CFU per gram) and at colon (9.3 vs. $8.3 \log _{10}$ CFU per gram) following daily administration of $9.5 \mathrm{~g}$ of oligofructose (Oli et al., 1998). At the same time, population of harmful bacteria i.e. Enterobacteria was reduced significantly at both caecum (6.2 vs. $7.4 \log _{10}$ CFU per gram) and colon (6.2 vs. $8.5 \log _{10}$ CFU per gram) in oligofructose piglets as compared to the piglets not receiving the prebiotics. There was significant increase in the population of total anaerobes, Bifidobacteria and lactobacilli with concomitant decrease in the number of Enterococci and Clostridium population following supplementation of prebiotic and probiotic (Nemcova et al., 1999). Contrary to this, some researchers did not find positive influence of prebiotics in animals. Replacing cellulose fraction with oligofructose in the diets of weanling pigs, neither altered the ileal population of total anaerobes nor lactobacilli (Houdijk et al., 1999). A non-significant increase in the population of Bifidobacteria was noticed at the ileal contents of weanling pigs by the same researchers. The pig waste is associated with malodor due to presence of microbial metabolites such as phenols, indoles, sulfides, fatty acids etc (Hobbs et al., 1996). Supplementation of chicory inulin in the diets of pig resulted in significant decrease of ammonia concentration in both caecum and colon (Mul, 1997). Consumption of prebiotics also enhanced both dry matter and organic matter digestibility at ileum (Houdijk , 1999).

For studying the effect of prebiotics on gastrointestinal worms, four month old pigs were challenged with lar- vae of Oesophagostomum dentatum (Petkevicius et al., 1997). The burden of worm was significantly lower in pigs consuming inulin as feed additives; indicating potentiality of prebiotic in prevention of parasitic infection. Weaned piglets consuming regularly oligofructose along with milk replacer could counteract the detrimental effect of challenged $E$. coli and exhibited increased survival rate, higher fecal concentration of Bifidobacteria and lower concentration of fecal E. coli (Bunce et al., 1995).

By virtue of prebiotic potentiality, inulin exhibited positive alteration of the gastrointestinal microflora which in turn demonstrated increased performance by livestock. On this aspect attempts were made to elucidate the effect of oligofructose on food intake and live weight gains in weaning pigs even before the introduction of prebiotic concept. No significant effect of either oligofructose or Jerusalem artichoke flour was noticed on feed intake, daily gains, and feed conversion efficiency in pig (Farmworth et al., 1992); as a result of insufficient levels of prebiotics. Later on, further studies revealed reduced dry matter intake, increased daily weight gains and feed conversions efficiency in growing pigs following supplementation of either oligofructose or trans-galactooligosaccharides (Houdijk et al., 1999).

\section{Poultry}

Like other animals, poultry also possesses a specialized organ (ceca) at the terminal part of the gastrointestinal tract to offer nutrient rich habitat for the millions of microflora ( $10^{11} \mathrm{CFU} / \mathrm{g}$ belonging to 200 or more strains) and to avail benefits of synergism from microbial fermentation (Timms, 1968). The microflora of the poultry caecum are broadly categorized into three: dominating, sub-dominating and temporary populations (Barnes, 1979). On the $1^{\text {st }}$ day of chick's life, the major caecum microflora includes species of Enterobacetriacae, Enterococcus and Lactobacillus. Bacteriodes and Eubacterium spp. got established after $2^{\text {nd }}$ weeks of chick's age (Van der Wielen et al., 2001).The microflora of the poultry gut is presumed to play multidimensional role including digestion, metabolism, pathogen exclusion, immune stimulation, vitamin synthesis etc. Under in vitro culture system, it has been noticed that Salmonella serotype could not grow in the presence of oligofructose as sole source of energy, while so called beneficial microflora namely Lactobacillus lactis, Entercoccus faecium and Pediococcus grow well by virtue of their ability to secrete enzymes competent to break down the osidic bonds present prebiotics (Oyarzabal and Conner, 1995). Therefore, it is noteworthy to incorporate inulin as prebiotic for overcoming Salmonella in chickens. Inclusions of oligofructose in the diets of chicks enabled substantially reduction in Salmonella colonization at the gastrointestinal tract (Bailey et al., 1991; Fukata et al., 1999).

Supplementation of inulin as prebiotics in the diet of layers and broiler birds improved growth performance (Verdonk and Van Leeuwen, 2004; Yusrizai and Chen, 
2003). Contradictorily, some of the research endeavor was unable to get a positive response on growth performance following inulin supplementation in birds (Biggs et al., 2007; Ortiz et al., 2009). The variability in the effectiveness of inulin may be ascribed to several factors namely level of inclusion, type of diet, animal individuality, degree of hygiene etc (Verdonk et al., 2005). The dietary inclusion of graded levels of inulin had no significant effect on the relative weight and relative length of the duodenum, jejunum, ileum and caecum of birds (Ortiz et al., 2009; Yusrizai and Chen, 2003). The inability of inulin to influence effectively the gross intestinal morphology might be a result of its high water solubility and its minimal capacity to increase the viscosity of the digesta (Schneeman, 1999).

Supplementation of broiler diets with prebiotic inulin showed no effect on the weight and measurement of tibia but linearly improved the relative apparent retention of $\mathrm{Ca}, \mathrm{Zn}$ and $\mathrm{Cu}$ (Ortiz et al., 2009). It increased the ash contents and $\mathrm{Ca}$ contents of tibia in broilers receiving inulin and established role of prebiotics on improvement of mineral utilization and bone mineralization (Figure 2). Inulin, being a prebiotic, is not digested by the birds own gastric or pancreatic enzymes but utilized by the specific group of microflora namely Bifidobacteria and Lactobacilli at the large intestine for production of various short chain fatty acids and lactic acids (Samanta et al., 2012). The production of fatty acids at large intestine leads to lowering of luminal $\mathrm{pH}$. Acidic $\mathrm{pH}$ is found to increase mineral solubility and facilitates higher mineral absorption (Levrat et al., 1991; Lopez et al., 2000). In this respect butyrate is more effective than acetate for ensuring higher $\mathrm{Ca}$ absorption.

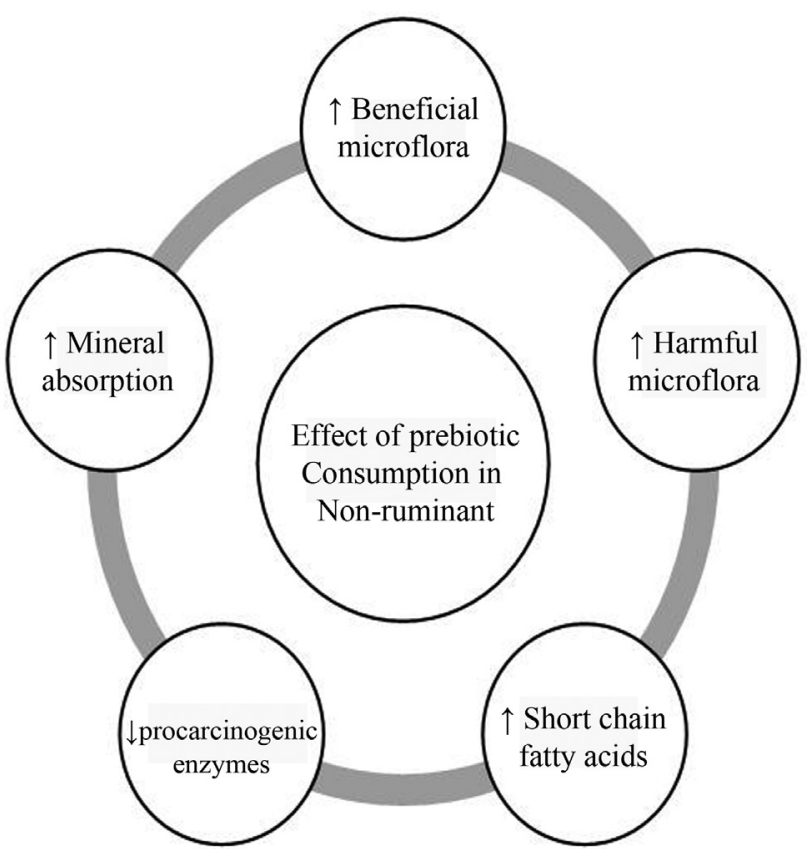

Figure 2 - Schematic diagram on effect of prebiotic consumption in non-ruminants.

\section{Dog}

Intake of oligofructose at a concentration of $1 \%$ of $\operatorname{diet}(\mathrm{w} / \mathrm{w})$ for a period of around 50 days significantly reduced the population of total gut aerobes, facultative aerobes in duodenal fluid and mucosa of German shepherd dogs suffering from intestinal bacterial overgrowth (Williard et al., 1994). It is presumed that supplemental oligofructose are preferentially fermented and utilized by Enterobacteria and Eubacteria strains which in turn prevent adhesion and survival of pathogenic bacteria in the colon of Beagles (Kearns et al., 1998). While incorporating graded levels of oligofructose in the diets of female hounds, there is significant decrease in the fecal concentration of Clostridium perfringens and increased concentrations of total aerobes and population of Bifidobacteria (Flickinger et al., 2002). In vitro fermentation of oligofructose in the presence of microflora of dog fecal matter leads to rapid production of short chain fatty acids including acetate, butyrate and propionate (Sunvold et al., 1995). Short chain fatty acids are supposed to possess trophic effect on the colonic epithelium (Flickinger, et al., 2003). Dogs consuming oligofructose had longer and heavier small intestine with greater available surface areas for absorption (Buddington et al., 1999). Fecal concentration of ammonia, putrescine, cadaverine, total phenols are found to be reduced following supplementation of oligofructose (Flickinger et al., 2002). These are the metabolites usually produced by the harmful bacteria inhabited at the gastrointestinal tract and supposed to be responsible for bad odor of feces or other detrimental consequences.

Consumption of inulin at a concentration of $7 \%$ of diet (w/w) exhibited no effect on apparent dry matter digestibility in dogs but digestibility of organic matter, crude protein, fat were lowered as compared to the control (Diez et al., 1998a). Contrary to the above, no difference in apparent dry matter, organic matter, crude protein or fat digestibility was observed following supplementation of various levels of oligofructose to the healthy dogs (Flickinger et al., 2002). Plasma cholesterol concentration of dogs reduced significantly following regular consumption of oligofructose for a period of 6 weeks (Diez et al., 1998b).

\section{Rabbit}

In case of rabbit, caecum is the primary site of fermentation which is carried out by several anaerobic genera (Flickinger et al., 2003). To have higher performances from rabbit, its diets are devised to be rich in protein and starch but low in fiber. Therefore, it seems the diet of rabbit should be enriched with sufficient quantities of fermentable carbohydrates (prebiotic) to maintain the homeostasis of gut microflora vis a vis its functionality. Thus oligofructose is routinely added at the levels of 1 to $3 \mathrm{~g} / \mathrm{kg}$ in European feeds in order to improve gut health and reduce mortality (Mul, 1997; Mul and Perry 1994). Fewer rabbits exhibited 
clinical symptoms of enteritis during E. coli induced diarrhoea following consumption of oligofructose unlike control animals (Morisse et al., 1993). Moreover rabbits consuming prebiotic oligosaccharides have higher body weights with higher average daily gains. Lower level of oligofructose in the diet of rabbits is capable of reducing the gastrointestinal $\mathrm{pH}$ as a result of production of short chain fatty acids from fermentation of prebiotics.

\section{Ruminant livestock}

The foregut and hindgut houses millions of diverse groups of microflora namely bacteria, fungi, yeasts, phage particles, archaea etc with the exception that protozoa are supposed to be present only at foregut and absent at hindgut. Prebiotics are fermented by number of rumen bacteria for its utilization as source of energy (Cota and Whitefield 1998; Samanta et al., 2012). The encouraging results of prebiotics on human health especially the gut microbial ecology have prompted ruminant researchers to explore its potentiality on different livestock species like cattle, buffalo, sheep etc. Ruminants are exposed to different kind of stress on different occasions like weaning, transportation, which adversely affect the health of the livestock, resulting in diarrhoea, off fed, depression of growth, impaired intestinal morphology etc (Fraser et al., 1998; Nabuurs, 1998). Under such situations, ecological treatment through prebiotic may be potential alternatives to overcome the gut associated problems of livestock.

Presently frugal information is available on the effects of prebiotic in ruminant animals. All the rumen hemicellulolytic bacteria are capable to utilize xylooligosaccharides as growth substrate (Cota and Whitefield, 1998). These are Butyrovibrio fibrisolvens, Eubacterium ruminantium, Ruminococcus albus etc. The rumen $\mathrm{pH}$ remained unchanged (6.7), when prebiotic is given to Holstein cows maintained on orchard grass silage or alfalfa silage (Santoso et al., 2003). In ruminant species, the above $\mathrm{pH}$ (6.6 to 6.8) is ideal for growth and multiplication of useful plant biomolecules degrading bacteria (Samanta et al., 2003). Some of the researchers did not notice any significant changes of rumen $\mathrm{pH}$ in steers supplemented with prebiotics; however, they recorded significantly higher oxidation reduction potential (Mwenya et al., 2004). The rumen ammonia nitrogen concentration was slightly lower in prebiotics supplemented Holstein cows and steers (Figure 3), which might be due to the utilization of ammonia for microbial protein synthesis in the rumen (Mwenya et al., 2005; Santoso et al., 2003). Lower rumen ammonia nitrogen concentration in sheep was also observed as a result of prebiotic administration, which may be due to the suppression of ammonia producing bacteria (Mwenya et al., 2004). Dry matter intake, nutrient digestibility is as such not affected by prebiotic supplementation but showed higher nitrogen retention owing to increased microbial protein synthesis in rumen (Santoso

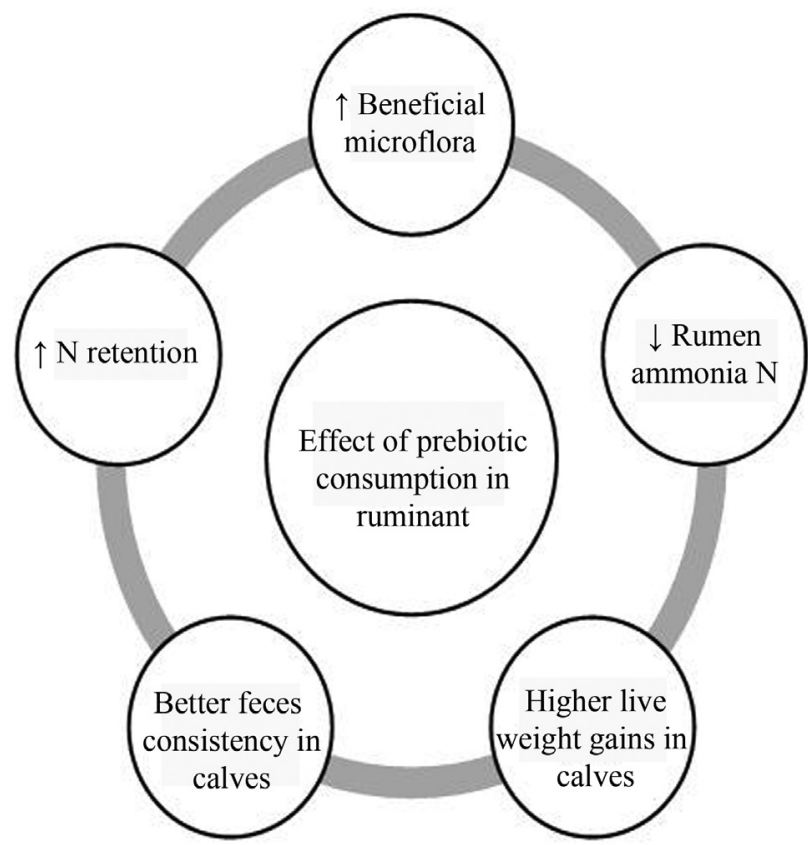

Figure 3 - Schematic diagram on effect of prebiotic consumption in ruminant.

et al., 2003). Inclusion of inulin in the milk replacer of pre-ruminant calves leads to significantly higher live weight gains, better feces consistency (Kaufhold et al., 2000; Verdonk and Van Leeuwen, 2004). It is postulated that increase in body weight might be ascribed due to increased fermentation at the small intestine followed by increased flow of microbial nitrogen at large intestine, stable microflora composition at rumen, small and large intestine of calves (Verdonk et al., 1998).

The fermentation of inulin is faster at $\mathrm{pH} 6.0$ than at neutral $\mathrm{pH}$ by rumen inoculums obtained from sheep maintained on sole forage diets (Flickinger et al., 2003). The diet of calves supplemented with oligofructose resulted in decreased population of fecal E. coli and total anaerobic microflora while Bifidobacteria population exhibited increasing trends (Bunce et al., 1995a). This might be attributed by beneficial effects brought out through the consumption of prebiotics followed by their fermentation at hindgut of calves. Incorporation of oligofructose in the milk replacer of calves resulted in improved body weight gains, feed conversion efficiency with reduction in the incidence of diarrhoea and firmer feces (Mul, 1997). Incorporation of fructooligosaccharides at a concentration of $0.5 \%$ to $1 \%$ of total mixed ration $(\mathrm{w} / \mathrm{w})$ significantly improved the organic matter and dry matter digestibility of total mixed ration by virtue of modulation of rumen metabolic profile (Samanta et al., 2012).

\section{Mechanism of action of prebiotics}

While forwarding the concept of prebiotic, Gibson and Roberfroid (1995) put the conditions for notifying a 
compound as a prebiotic; it must be indigestible by gastrointestinal enzymes but categorically utilized by selective group of gut beneficial microflora. Unlike other functional foods, prebiotics exhibit multi-dimensional activities beginning from modulation of gut microflora to mineral absorption, pathogen exclusion etc (Roberfroid, 2002; Rycroft et al., 2001; Samanta et al., 2010). Therefore, to bring out its positive influence on the livestock system, the channel of activities is supposed to be widely distributed amongst several systems including gastrointestinal, immune regulatory, skeletal organs etc. From the literature it is evidenced that prebiotics are getting its niche for routine consumption for gut health as well as management of gastrointestinal disorders. Obviously most of the studies towards unfolding the mechanism of prebiotic actions are carried out in laboratory animals i.e. mice or rats with subsequent support through investigating under in vitro or human volunteers. Under such circumstances mechanism of prebiotic function are discussed under the following aspects.

\section{Trophic effect}

To elucidate the trophic action of oligofructose, piglets were raised with a diet ensuring regular consumption of 1.4 g oligofructose (Howard et al., 1995). There was significant increase of caecum mucosal cell density (40.4 vs. 44.7cells/crypt) along with significantly higher number of labeled cells (8.2 vs. 9.6 cells/crypt). Proximal colonic mucosal crypt depth, labeled cells, proliferation zone, labeling index were exhibited to increase as a result of oligofructose supplementation as compared to control piglets. Similarly, at the distal colon, intake of oligofructose permeate to have increased mucosal crypt depth, cell density, labeling index, number of labeled cells and proliferation zone. It seems consumption of prebiotic oligofructose enhances indices of epithelial cell proliferation throughout the full length of large intestine in piglets (Flickinger et al., 2003). The direct trophic effect on colonic mucosa was later on substantiated on rat model by supplementing its diet with chicory inulin and oligofructose or pectin (Poldbeltsev et al., 2006). There was increase in number of epithelial cells and its secretion capacities, length and width of colonic crypts followed by increased areas of nutrient absorption including micronutrients and minerals. Further studies in rat caecum and colonic mucosa noticed that 2.2 times increase in macroscopic areas, 2.4 times increase in tissue wall weight following intake of prebiotic containing FOS and inulin (Raschka and Deniel 2005). Significant increase in crypt depth $(\mathrm{p}<0.001)$ and goblet cell numbers $(\mathrm{p}<0.001)$ at caecum epithelium were recorded in male Sprawley Dawley rats while administering prebiotics (Mineo et al., 2006). Studies on supplementation of yacon flour in the diet of male wistar rats showed increased number of bifurcating crypts for enlargement of absorbing surface in the large intestine of the animals (Lobo et al., 2007). This might be resulted from elevated epithelial cell proliferation and crypt fission (Mandir et al., 2008).

By virtue of hydrolysis and utilization of prebiotic at lower gut of animals, a variable quantities of short chain fatty acids (acetate, butyrate and propionate) along with acid lactic are produced and subsequently reduces the lumen $\mathrm{pH}$. Amongst those fatty acids, butyric acid is reported to possess strong trophic actions for stimulation of mucosal proliferation (Blottiere et al., 2003). On the other hand lactic acid could stimulate mitosis in the rat caecum epithelium (Ichikawa and Sakata 1997). Above theory of trophic functions are further confirmed when germfree animals failed to exhibit trophic effects at large intestine following consumption of prebiotics; substantiating the microbial generation of fatty acids from prebiotics are utmost to demonstrate the above functionality. The permeability of paracellular pathway is dependent on tight junctions that linked between adjacent epithelial cells and large multi-protein complex (Steed and Macfarlane 2009). Application of non-digestible oligosaccharides in the caco-2 intestinal cell line model, there was rapid increase in paracellular ion transport because prebiotics may increase the permeability of paracellular pathways.

\section{Mucus}

The goblet cells present at the gut epithelial lining secretes cysteine rich glycoprotein (high molecular weight), known as mucus. The major function of the mucus is to form a slimy layer along the entire mucosal surface and often considered as first line of defense of the intestine. Although thickness of mucus varies along the length of the gastrointestinal tract, it is thickest at the distal part of the intestine. In spite of being a rich source of nitrogen and energy, very few gastrointestinal microfloras is capable to secrete necessary enzymes for the degradation of mucus. The bacterial flora plays a significant role in the distribution of different types of mucus. In the small intestine, concentration of neutral and sulphomucin is higher, whereas sialomucin is lower. Conversely, concentration of sialomucin is higher in the caecum and colonic mucosa, whereas concentration of sulphated mucin is decreased significantly in caecum and colonic mucosa (Meslin et al., 1999). Administration of prebiotics caused thickening of mucus layer as well as increased secretion of goblet cells (Steed and Macfarlane, 2009).

\section{Hydrolysis of phytic acid}

Phosphorus is present in plants either in phytate or phytic acid form. Usually phytate or phytic acid of plant are subject to microbial degradation for further release of phosphorus in the reticulo-rumen of ruminant species unlike mono-gastric livestock. In the latter animals, phytate binds with minerals like $\mathrm{Zn}, \mathrm{Ca}$ and $\mathrm{Fe}$ for making these unavailable for absorption. Similarly, phytic acid is also capable of reducing Fe absorption as well as its availability at gastroin- 
testinal tract. Consumption of prebiotics is reported to show stimulatory effects on iron absorption by increasing soluble fractions of iron at large intestine. Addition of fructooligosaccharides restores zinc absorption by enhancing zinc bioavailability in human and rats. Supplementation of prebiotic in the diet of rats substantially reduces the phytate concentration of feces as it is hydrolyzed in greater concentration through increased and altered gut microflora. Short chain fatty acids produced by gut microflora forms soluble ligands with cation and prevents the formation of insoluble mineral phytate complex (Steed and Macfarlane, 2009).

\section{Modulation of gut microflora}

By virtue of its definition, prebiotics consumption leads to modulation of gut microflora composition towards higher growth and multiplication of beneficial category namely Bifidobacteria and Lactobacilli (Gibson et al., 2004; Samanta et al., 2011). These bacteria are often considered as friendly bacteria as they are capable of fermenting nondigestible carbohydrates, reduces gut $\mathrm{pH}$, produces short chain fatty acids, help in competitive exclusion of pathogens, stimulates immunoglobulin production etc. Prebiotics are being fermented at large intestine into short chain fatty acids like acetate and butyrate; energy source for the host. Although Bifidobacteria is not able to produce butyrate through its fermentative metabolism but it stimulates other butyrate producing bacteria like Eubacteria, inhabited at the gastrointestinal tract (Belenguer et al., 2006). The short chain fatty acids have multidimensional role including growth and cellular differentiation, colonic epithelial cell transport, lipid metabolism, carbohydrate metabolism etc. On the other hand, prebiotics are able to reduce the population of harmful gut microflora namely Clostridium, Bacteroides, Enterococcus, Enterobactericea etc. Obviously concentration of toxic metabolites (ammonia, indoles, phenols, thiols, etc.) generated through action of those harmful bacteria are substantially reduced following consumption of prebiotics. Some of these toxic metabolites are also carcinogenic. Therefore prebiotic consumption reduces population of harmful bacteria in the gastrointestinal tract followed by reduced production of toxic microbial metabolites vis a vis reduced incidence of colorectal cancer. As each strain of beneficial gut microflora has specificity on substrate utilization, all the prebiotics do not equally stimulate the growth and multiplication of complete set of beneficial gut microflora. Prebiotic potentiality depends upon several factors namely degree of polymerization, composition, availability of other carbohydrates, quantity of consumption and so on. Consumption of inulin and fructooligosaccharides increased mucosal population of Bifidobacteria and Eubacteria (Langlands et al., 2004). Similarly, under in vitro system, fructooligosaccharides derived from chicory roots were found to increase significant growth of Lactobacillus plantarum and Enteroccus faecelis (Samanta et al., 2012). Recently, it has come to notice that prebiotics are also de- graded by other gut commensal microflora such as Faecalibacterium prausnitzii and the end product of fermentation is butyrate (Ramirez-Farias et al., 2009).

\section{Immune modulation}

By modulating the composition and functionality of microflora, dietary inclusion of prebiotics modulates the immune system and host defense system in addition to its potentiality to exclude the gut pathogens through competitive exclusion (Lomax and Calder, 2008). Mode of this action is still not clear and it is doubtful whether it is direct or indirect effect aroused from stimulation of immunemodulating microflora or production of short chain fatty acids. Short chain fatty acids stimulate the goblet cells for increasing secretion of mucin and decreasing translocation by binding to specific receptors like G-protein coupled receptor 41 (Gpr41) of immune cells located at the gut lymphoid associated tissue (GALT) (Brown et al., 2003). Besides, there has been increased mucosal immunoglobulin production and altered cytokine formation in the spleen and intestinal mucosa (Schley and Field, 2002).

\section{Lipid metabolism}

Consumption of prebiotics is reported to lower the concentration of both cholesterol and triglycerides; indicating a greater significance for their lipidemia and cardiovascular benefits in both animals and human (Jackson et al., 1987, 1999). Oligofructose supplementation in rats resulted in significant reduction of serum phospholipids and triglycerols especially very low density lipoprotein (VLDL). This is mediated through the reduced activities of hepatic lipogenic enzymes namely FAS, malic enzymes, ATP citrate lyase, acetyl-coA carboxylase, glucose -6 -phosphate 1-dehydrogenase, fatty acid synthase mRNA (Fiordaliso et al., 1995; Kok et al., 1996). It is suggested that prebiotics may modify gene expression of lipogenic enzymes. In rat maintained on high fat diet, prebiotics regulates the plasma free cholesterol levels; implicating its extra-hepatic regulation of lipid metabolism. It seems that prebiotic effect might link with insulin, which potentiates the gene expression effects. Consumption of prebiotics resulted in short chain fatty acids (acetate, propionate, butyrate etc.) production at gut lumen followed by their increased concentration. Propionate is found to inhibit synthesis of fatty acids in vivo. Butyrate is the preferable source of energy for enterocyte of gut epithelium. Following absorption of acetate, it enters into the hepatocyte for taking part in lipogenesis. Propionate competes with the protein that regulates acetate entry into the hepatocyte cells. Therefore prebiotic regulates the acetate and propionate ratio in the cells and exhibits its control over lipid metabolism.

\section{Mineral metabolism}

Prebiotic shows its positive influence on livestock by increasing absorption of $\mathrm{Ca}, \mathrm{Mg}, \mathrm{Fe}, \mathrm{Zn}$ at gastrointestinal 
tract and bone mineralization. Both in broilers and layers, inulin is found to exhibit positive effect on mineral balance especially Ca, P, Zn (Swiatkiewicz et al., 2010; Ortiz et al., 2009). Solubility of $\mathrm{Ca}$ is higher in acidic $\mathrm{pH}$ (Dupuis et al., 1978). Production of short chain fatty acids by beneficial gut microflora from degradation of prebiotics reduces the luminal $\mathrm{pH}$ at lower part of large intestine and this might be the reason for higher $\mathrm{Ca}$ retention following prebiotic supplementation in broilers. Acidic $\mathrm{pH}$ brought out by fermentation of prebiotic at lower part of large intestine leads to increased solubility of $\mathrm{Ca}$ as well as increased gradient across the epithelium; which further promotes passive uptake of the element. However, some school of thought believed in divalent ion transport mechanism for prebiotic induced higher Ca retention (Raschka and Deniel, 2005). Addition of short chain fatty acids at rat mucosal epithelium increases the permeability and decrease the electrical resistance. Therefore, it is hypothesized that prebiotic interact with tight epithelial junctions and increase the permeability for minerals entry. The mechanism of the beneficial influence of inulin on mineral utilization is complex and might happened as a result of increased solubility of minerals owing to the increased production of short chain fatty acids from degradation of inulin. Additionally higher mineral absorption is attributed also by alteration of intestinal mucosa, increased absorption surface areas by means of beneficial effects of bacterial fermentation products on the proliferation of enterocytes, increased expression of calcium binding proteins, release of bone modulating factors, degradation of phytates and overall improvement of gut health (Swiatkiewicz et al., 2010).

Another hypothesis for higher mineral absorption considers that colonic uptake of $\mathrm{Ca}$ take place along with uptake of short chain fatty acids. Moreover, prebiotic fermentation regulates the gene expression of proteins that are linked to sequestration and mucosal ion binding. It is noteworthy to say that chain length or type of branching of prebiotic fructan did not influence the degree of increased mineral absorption. Lactate pool of gut in combination with lumen $\mathrm{pH}$ significantly affects the absorption of $\mathrm{Mg}$. Other school of thought endorsed the role of short chain fatty acids for increased $\mathrm{Mg}$ absorption through activation of $\mathrm{Mg}^{2+} / 2 \mathrm{H}^{+}$antiport. Among the various short chain fatty acids, butyrate is the potent stimulant for the magnesium flux from the mucosal to serosal direction (Kashimura et al., 1996).

\section{Anti-carcinogenesis}

The typical lifespan of livestock and birds does not offer enough scope for the development of colon cancer. However, in some instances other forms of tumor are often noticed in domestic animals. Research findings on gut ecology revealed production of several mutagenic products from the microbial fermentation of plant biomolecules in the gastrointestinal tract in addition to secretion of enzymes responsible for conversion of pro-carcinogens to carcinogens. A few of the gut microbial metabolites possessing carcinogenic properties are nitrosamine, phenols, cresols, indole, skatole, estrogens, secondary bile acids, aglycones etc (Bingham, 1988; Flickinger et al., 2003). Gut microflora actively participate in the formation of those carcinogenic metabolites are E. coli, Clostridium spp., Bacteroides spp., Streptococcus fecalis, Proteus spp. (Tomomatsu, 1994). The administration of prebiotics in the diet of animals modulate the gut microflora towards higher population of Bifidobacteria as well as lactobacilli, which in turn reduces the population of those harmful bacteria as well as creates a microenvironment unsuitable for growth and multiplication of harmful bacteria.

\section{Conclusion}

For several decades, antibiotics and chemotherapeutic agents in prophylactic dose were used in livestock feed to improve the productivity and to ensure higher economic returns. Following a ban over the application of antibiotics in the diet of livestock coupled with growing concerns of residues, livestock managers are now looking towards ecological feed additives. The application of prebiotics in the diets of livestock is a relatively recent endeavor and many issues are still unresolved even though the available data are promising. At the same time increasing consumer awareness for health and nutritional issues makes the emerging market for prebiotics very promising. However, till date the product cost of prebiotics is very high and beyond the reach of common livestock farmers. At the same time, there is urgent need of scientific research to establish the efficacy of prebiotics in routine diets of livestock and to develop cost effective processes for prebiotic production at industrial scale.

The gut of newly born livestock or newly hatched chick is sterile and colonization with diverse groups of microflora takes place following contact between newborn and its environment, mode of delivery/ hatching conditions, hygiene levels, medication, type of feeding etc. It has often been commented that more than $90 \%$ of the total cells of healthy individual belongs to bacterial cells, largely present in the gastrointestinal tract. In terms of perspectives, the future research on prebiotics as functional food ingredients relies on the following: (i) development of process for cost effective production of prebiotics, (ii) unraveling the mechanism of action and (iii) generation of scientific evidences for elucidating the prebiotic potentiality on animal systems especially the production quality and quantity. Prebiotics might be the prime choice from the basket of functional foods as it exhibits its significance through multifarious means. Future research should substantiate prebiotic effect on microflora with application of advanced techniques like next generation sequencing (NGS). Additionally future research of prebiotic application in livestock should consider immunological aspects, 
livestock product quality, changes at gut epithelial tissues, therapeutic aspects with more emphasis on common gastrointestinal disorders.

\section{Acknowledgement}

The authors acknowledge the financial support (BT/PR10518/AAQ/01/361/2008) received from Department of Biotechnology, Ministry of Science and Technology, Government of India. The authors express their gratitude to Dr. K.T. Sampath, Director for his constant encouragement and whole hearted support for undertaking the preparation of manuscript.

\section{References}

Aida FMNA, Shuhaimi M, Yazid M, Maaruf AG (2009) Mushroom as potential source of prebiotic: A review. Trends Food Sci Technol 20:567-575.

Bailey JS, Blankenship IC, Cox NA (1991) Effect of fructooligosaccharides on salmonella colonization of the chicken intestine. Poultry Sci 70:68(suppl.):167.

Barnes EM (1979) The nutritional significance of dietary fiber analysis. Anim Feed Sci Technol 90:3-20.

Belenguer A, Duncan SH, Calder AG, Holtrop G, Louis P, Loblet GE, Flint HJ (2006) Two routes of metabolic cross feeding between Bifidobacteria adolescentis and butyrate producing anaerobes from the gut. Appl Environ Microbiol 72:35933599.

Biggs P, Parsons CM, Fahey CC (2007) The effects of several oligosaccharides on growth performance, nutrient digestibility and cecal microbial populations in young chicks. Poultry Sci $86: 232-242$.

Bingham SA (1988) Meat, starch and non-starch polysaccharides and large bowel cancer. Am J Clin Nutr 44:21-27.

Blottiere HM, Buecher B, Galmcihe JP, Cherbut C (2003) Molecular analysis of the effect of short chain fatty acids on intestinal cell proliferation. Proc Nutr Soc 62:101-106.

Brown AJ, Goldsworthy SM, Barnes AA, Eilert MM, Tcheang I, Daniels D, Muir AI, Wigglesworth MJ, Kinghorn I, Fraser NJ, Pike NB, Strum JC, Steplewiski KM, Murdock PR, Holder JC, Marshall FH, Szekeres PG, Wilson S, Ignar DM, Foord SM, Wise A, Dowell SJ (2003) The orphan G protein - coupled receptors GPR41 and GPR 43 are activated by propionate and other short chain carbosylic acids. J Biol Chem 278:11312-11319.

Buddington RK, Buddington KK, Sunvold GD (1999) Influence of fermentable fiber on small intestinal dimensions and transport of glucose and proline in dogs. Am J Vet Res 60:354-358.

Bunce TJ, Howard MD, Kerley MS, Allee GI, Pace LW (1995) Protective effect of fructooligosaccharides (FOS) in prevention of mortality and morbidity from infectious E. coli K88. J Anim Sci 73 (Suppl 1):69.

Bunce TJ, Howard MD, Kerley MS, Allece GI (1995a) Feeding fructooligosaccharides to calves increased Bifidobacterium and decreased Escherichia coli. J Anim Sci 73(suppl):281.
Carpita NC, Kanabus J, Housley TL (1989) Linkage structure of fructans and fructan oligomers from Triticum aestivum and Festuca arundinacea leaves. J Plant Physiol 134:162-168.

Cota MA, Whitefield TR (1998) Xylooligosaccharides utilization by ruminal anaerobic bacterium Selemonas ruminantium. Curr Microbiol 36:183-189.

Diez M, Hornick JL, Baldwin P, Van Eenaeme C, Istasse I (1998a) The influence of sugar beet fibre, guar gum, and inulin on nutrient digestibility, water consumption and plasma metabolites in healthy beagle dogs. Res Vet Sci 64:9196.

Diez M, Hornick JL, Baldwin P, Van Eenaeme C, Istasse I (1998b) Etude des fibres alimentaires chez le chien: Presentation des resultants decssais experimentaux. Ann Med Vet 142:185-201.

Dupuis Y, Digaud A, Fournier P (1978) The relations between intestinal alkaline phosphatase and carbohydrates with regard to calcium absorption. Arch Int Physiol Biochem 86:543556.

FAO (2007) FAO technical meeting on prebiotics, available at http://www.fao.org/ag/agn/files/prebiotics_tech_meeting_report.pdf.

Farmworth ER, Modler HW, Jones JD, Cave N, Yamazaki H, Rao AV (1992) Feeding Jerusalem artichoke flour rich in fructooligosaccharides to weanlings pigs. Can J Anim Sci 72:977-980.

Fiordaliso M, Kok N, Desager JP, Goethals F, Deboyser D, Roberfroid M, Delzenne N (1995) Dietary oligofructose lowers triglycerides, phospholipids and cholesterol in serum and very low density lipoproteins of rats. Lipids 30:163-167.

Flickinger EA, Hatch TF, Wofford RC, Grieshop CM, Murray SM, Fahey Jr GC (2002) In vitro fermentation properties of selected fructooligosaccharides containing vegetables and in vivo colonic microbial populations are affected by diet in healthy human infants. J Nutr 132:2188-2194.

Flickinger EA, Van Loo J, Fahey Jr GC (2003) Nutritional responses to the presence of inulin and oligofructose in the diets of domesticated animals: A review. Crit Rev Food Sci Nutr 43:19-60.

Franck AME (2000) Inulin and oligofructose. In: Gibson G, Angus $\mathrm{F}$ (eds) LFRA Ingredient Handbook: Prebiotics and Probiotics. Leatherhead Publishing, Surrey, pp 1-18.

Fraser D, Milligan BN, Pajor EA, Philips PA, Taylor AA, Weary MA (1998) Behavioral perspectives on weaning in domestic pigs. In: Varley MA, Chadwick JP (eds), Pig Science. Nottingham University Press, Nottingham, pp 121-138.

Fukata T, Sasai K, Miyamoto T, Baba E (1999) Inhibitory effects of competitive exclusion and fructooligosaccharides, singly and in combination on Salmonella colonization of chicks. J Food Prot 62:229-233.

Gibson GR, Probert HM, Rastall RA, Roberfroid MB (2004) Dietary modulation of the human colonic microbiota: Updating the concept of prebiotics. Nutr Res Rev 17:259275.

Gibson GR, Roberfroid MB (1995) Dietary modulation of the human colonic microbiota: Introducing the concept of prebiotics. J Nutr 125:1401-1412. 
Gill SR, Pop M, Deboy RT, Ecburg PB, Turnbaugh PJ, Samuel BS, Gordon JI, Relman DA, Fraser-Liggett CM, Nelson KE (2006) Metagenomic analysis of the human gut microbiome. Sci 312:1355-1359.

Harmsen HJ, Gibson GR, Elfferich P, Raangs GC, Wildeboerveloo AC, Argaiz A, Roberfroid MB, Welling GW (2000) Comparison of viable cell counts and fluorescence in situ hybridization using specific rRNA based probes for the quantification of human fecal bacteria. FEMS Microbiol Lett 183:125-129.

Hendry G (1987) The ecological significance of fructan in a contemporary flora. New Physiol 106:201-216.

Hobbs PJ, Pain BF, Kay RM, Lee PA (1996) Reduction of odorous compounds in fresh pig slurry by dietary control of crude protein. J Sci Food Agric 71:508-514.

Hobson NP, Hobson PN, Stewart CS (1988) Rumen Microbial Ecosystem. Springer, Netherlands, $540 \mathrm{pp}$.

Houdijk JG, Bosch MW, Tamminga S, Verstegen MW, Berenpas EB, Knoop H (1999) Apparent ileal and total tract nutrient digestion by pigs as affected by dietary non-digestible oligosaccharides. J Anim Sci 77:148-158.

Howard MD, Gordon DT, Pace IW, Garleb KA, Kerley MS (1995) Effects of dietary supplementation with fructooligosaccharides on colonic microbiota populations and epithelian cell proliferation in neonatal pigs. J Pediatr Gastroenterol Nutr 21:297-303.

Hungate RE (1966) The Rumen and its Microbes. Academic Press, New York, 533 pp.

Ichikawa H, Sakata T (1997) Effect of L-lactic avid, short chain fatty acids and $\mathrm{pH}$ in cecal infusate on morphometric and cell kinetics parameters of the rat caecum. Dig Dis Sci 42:1598-1610.

Jackson JL, Lairon D, Borel P, Portugal H, Pauli AM, Hauton JC, Layfont H (1987) Effect of pectin, wheat bran, and cellulose on serum lipids and lipoproteins in rats fed on a low or high fat diet. Br J Nutr 58:405-413.

Jackson KG, Taylor GRL, Clohessy AM, Williams CM (1999) The effect of the daily intake of inulin on fasting lipid, insulin and glucose concentrations in middle aged men and woman. Br J Nutr 82:23-30.

Kashimura J, Kimura M, Jtokawa Y (1996) The effects of isomaltose, isomalt and isomaltose based oligomers on mineral absorption and retention. Biol Trace Elem Res 54:239-250.

Kaufhold JN, Hammon HM, Blum JW (2000) Fructooligosaccharides supplementation effects on metabolic, endocrine and hematological traits in vela calves. J Vet Med A 47:17-29.

Kearns RJ, Hayek MG, Sunvold GA (1998) Microbial changes in aged dogs. In: Reinhart GA, Carey DP (eds), Recent Advance in Canine and Feline Nutrition: Iams Nutritional Symposium Proceedings. Orange Frazer Press, Wilmington, pp 337-351.

Kok N, Roberfroid M, Delzenne N (1996) Involvement of lipogenesis in the lower VLDL secretion induced by oligofructose in rats. Br J Nutr 76:881-890.

Laden G, Wrangham R (2005) The rise of the hominids as an adaptive shift in fallback foods: Plant underground storage organs (USOs) and australpith origins. J Hum Evol 49:482498.
Langlands SJ, Hopkins MJ, Coleman N, Cummings JH (2004) Prebiotic carbohydrates modify the mucosa associated flora of the large bowel. Gut 53:1610-1616.

Leach JD (2007) Prebiotics in ancient diets. Food Sci Technol Bull: Functional Foods 4:1-8.

Leach JD, Gibson GR, Van Loo J (2006) Human evolution, nutritional ecology and prebiotics in ancient diets. Biosci Microflora $25: 1-8$.

Levrat MA, Remesy C, Sorensen P (1991) High propionic acid fermentation and mineral accumulation in the caecum of rats adapted to different levels of inulin. J Nutr 121:1730-1737.

Lobo AR, Colli C, Alvares EP, Filisetti TM (2007) Effects of fructans-containing yacon (Smallanthus sonchifolius Poepp and Endl) flour on caecum mucosal morphometry, calcium and magnesium balance, and bone calcium retention in growing rats. Br J Nutr 97:776-785.

Lomax AR, Calder PC (2008) Prebiotics, immune function, infection and inflammation: A review of the evidence. Br J Nutr 101:633-658.

Lopez HW, Coudray C, Levrat-Verney M, Feillet-Coudray C, Demigne C, Remesy C (2000) Fructooligosaccharides enhance mineral apparent absorption and counteract the delketorius effect of phytic acid on mineral homeostasis in rats. $\mathrm{J}$ Nutr Biochem 11:500-508.

Mandir N, Englyst H, Goodlad RA (2008) Resistant carbohydrates stimulate cell proliferation and crypt fission in wildtype mice and in the Apc mouse model of 22intestinal cancer, association with enhanced polyp development. Br J Nutr 100:711-721.

Meslin JC, Fontaine N, Andrieux C (1999) Variation of mucin distribution in the rat intestine, caecum and colon: Effect of the bacterial flora. Comp Biochem Physiol A 123:235-239.

Mineo H, Amano M, Minaminida K, Chiji J, Shigematsu N, Tomita F, Hara H (2006) Two week feeding of di-fructose anhydride $\mathrm{H} 1$ enhances calcium absorptive activity with epithelial cell proliferation in isolated rat cecal mucosa. Nutr 22:312-320.

Morisse JP, Maurice R, Boiletot E, Cotte JP (1993) Assessment of the activity of fructooligosaccharide on different cecal parameters in rabbits experimentally infected with $E$. coli O103. Ann Zootech 42:81-87.

Moxley RA, Duhamal GE (1999) Comparative pathology of bacterial enteric diseases of swine. Adv Exp Med Biol 473:83101

Mul AJ (1997) Application of oligofructose in animal feeds. In: Proceedings of International Symposium Non-Digestible Oligosaccharides: Healthy Food for colon? Wageningen, The Netherlands, pp 106.

Mul AJ, Perry FG (1994) The role of fructooligosaccharides in animal nutrition. In: Garnsworthy PC, Cole D.J.A (eds), Recent Advances in Animal Nutrition. Nottingham University Press, Nottingham, pp 57-79.

Mwenya B, Santoso B, Sar C, Gamo Y, Kobayashi T, Arai I, Takahashi J (2004) Effects of including beta 1,4- galactooligosaccharides, lactic acid bacteria or yeasts culture on methanogenesis as well as energy and nitrogen metabolism in sheep. Anim Feed Sci Technol 115:313-326.

Mwenya B, Sar C, Santoso B, Gamo Y, Kobayashi T, Morikawa R, Takura K, Umetsu K, Kogawa S, Kimura K, Mizukoshi 
H, Takahashi J (2005) Comparing the effects of beta 1,4-galactooligosaccharides, and L-cysteine to monensin on energy and nitrogen utilization in steers fed a very high concentrate diets. Anim Feed Sci Technol 118:19-30.

Nabuurs MJA (1998) Weaning piglets as a model for studying pathophysiology of diarrhoea. Vet Q 20:42-45.

Neish AS (2009) Microbes in gastrointestinal health and disease. Gastroenterol 136:65-80.

Nemcova R, Bomba A, Gancarikova S, Herich R, Guba P (1999) Study of the effect of Lactobacillus paracasei and fructooligosaccharides on the fecal microflora in weanling piglets. Berl Munch Teraarzil Wschr 112:225-228.

Niness KR (1999) Nutritional and health benefits of inulin and oligofructose. J Nutr 129:1402S-1406S.

Oli MW, Petschow BW, Buddington RK (1998) Evaluation of fructooligosaccharides supplementation of oral electrolyte solutions for treatment of diarrhea. Dig Dis Sci 43:138-147.

Ortiz LT, Rodriguez ML, Alzueta C, Rebole A, Trevino J (2009) Effect of inulin on growth performance, intestinal tract size, mineral retention, and tibial bone mineralization in broiler chickens. Br Poultry Sci 50:325-332.

Oyarzabal OA, Conner DE (1995) In vitro fructooligosaccharides utilization and inhibition of Salmonella spp. by selected bacteria. Poultry Sci 74:1418-1425.

Petkevicius S, Knudsen BKE, Nansen P, Roepstorff A, Skjoth F, Jensen K (1997) The impact of diets varying in carbohydrates resistant to endogenous enzymes and lignin on population of Ascaris suum and Oesophagostomum dendatum in pigs. Parasitol 114:555-568.

Poldbeltsev DA, Nikitiuk DB, Pozdniakov AL (2006) Influence of prebiotics on morphological structre of the mucous membrane of intestinal crassum of rats. Voper Pitan 75:26-29.

Pope MJ, Cherry TE (2000) An evaluation of the presence of pathogens on broilers raised on poultry litter treatmenttreated litter. Poultry Sci 79:1351-1355.

Ramirez-Farias C, Slezak K, Fuller Z, Duncan A, Holtrop G, Louis P (2009) Effect of inulin on the human gut microbiota: Stimulation of Bifidobacterium adolescentis and Faecalibacterium prausnitzii. Br J Nutr 101:541-50.

Raschka L, Deniel H (2005) Mechanism underlying the effects of inulin types fructans on calcium absorption in the large intestine of rats. Bone 37:728-735.

Roberfroid M (2002) Functional food concept and its application to prebiotics. Diges Liver 34(suppl 2):105-110.

Roberfroid M (2007) Prebiotics: The concept revisited. J Nutr 137:830S-837S.

Rycroft CE, Jones MR, Gibson GR, Rastall RA (2001) A comparative in vitro evaluation of the fermentation properties of prebiotic oligosaccharides. J Appl Microbiol 91:878-887.

Saito Y, Takano T, Rowland I (1992) Effect of soybean oligosaccharides on the human gut microflora in in vitro culture. Microbiol Ecol Health Dis 5:105-111.

Samanta AK, Senani S, Kolte AP, Sridhar Manpal Bhatta R, Jayapal Natasha (2012) Effect of prebiotic on digestibility of total mixed ration. Indian Vet J 89:41-42.

Samanta AK, Kolte AP, Senani S, Sridhar Manpal, Jayapal Natasha (2011) Prebiotics in ancient Indian diets. Curr Sci 101:43-46.
Samanta AK, Senani S, Kolte AP, Sridhar Manpal, Jayapal Natasha (2010) Application of prebiotics in poultry. Agrovet Buzz 3:38-42.

Samanta AK, Kolte AP, Chandrasekharaiya M, Thulasi A, Sampath KT, Prasad CS (2007) Prebiotics: The rumen modulator for enhancing the productivity of dairy animals. Indian Dairyman 59:58-61.

Samanta AK, Senani S, Kolte AP, Sridhar Manpal, Sampath KT, Jayapal Natasha, Anusuya Devi (2012) Production and in vitro evaluation of xylooligosaccharides generated from corn cobs. Food Bioprod Process 90:466-474.

Samanta AK, Singh KK, Das MM, Maity SB, Kundu SS (2003) Effect of complete feed block on nutrient utilization and rumen fermentation in Barbari goats. Small Ruminant Res 48:95-102.

Sangeetha PT, Ramesh MN, Prapulla SG (2005) Maximization of fructooligosaccharides production by two stage continuous process and its scale up. J Food Eng 68:57-64.

Santoso B, Kume S, Nonaka K, Gamo Y, Kimura K, Takashi J (2003) Influence of beta galactooligosaccharide supplementation on nitrogen utilization, rumen fermentation, and microbial nitrogen supply in dairy cows fed silage. Asia Austr J Anim Sci 26:1137-1142.

Schley PD, Field CJ (2002) The immune enhancing effects of dietary fibres and prebiotics. Br J Nutr 87:S221-S230.

Schneeman BO (1999) Fiber, inulin and oligofructose: Similarities and differences. J Nutr 129:1424S-1427S.

Steed H, Macfarlane S (2009) Mechanism of prebiotic impact on health. In: Charalampopoulos D, Rastall RA (eds), Prebiotics and Probiotics Science and Technology. Springer Publications, New York, pp 135-161.

Sunvold GD, Fahey Jr GC, Merchen NR, Titgemeyer EC, Bourquin ID, Baur LL, Reinhart GA (1995) Dietary fiber for dogs, IV. In vitro fermentation of selected fiber sources by dog fecal inoculums and in vivo digestion and metabolism of fiber supplemented diets. J Anim Sci 73:1099-1109.

Swiatkiewicz S, Koreleski J, Arczewska-Wlosek A (2010) Effect of prebiotic fructan and organic acids on mineral retention in laying hens. Acta Agric Scand A 60:125-128.

Timms I (1968) Observations on the bacterial flora of the alimentary tract in three age groups of normal chickens. Br Vet J 124:470-477.

Tomomatsu H (1994) Health effects of oligosaccharides. Food Technol 48:61-65.

Van der Wielen PW, Biesterveld S, Notermans S, Hofstra H, Urlings BAP, Van knapen F (2001) Inhibition of glucose limited sequencing fed batch culture of Salmonella enteric Setrovar Enteritidis by volatile fatty representative of the ceca of broiler chickens. Appl Environ Microbiol 67:19791982.

Van Loo J, Coussement P, De Leenheer L, Huybregs H, Smits G (1995) On the presence of inulin and oligofructose as natural ingredients in the western diets. Crit Rev Food Sci Nutr 35:525-552.

Verdonk JMAJ, Beelan GM, Jansman AJM, Huisman J (1998) Effect of soya carbohydrate fractions on the ileal digestibility and endogenous flow of nitrogen in veal calves. In: Jansman AJM, Hill GD, Huisman J, Vander Poel AFB (eds), 
Recent Advances of Research in Antinutritional Factors in Legume Seeds. Wageningen, The Netharlands, pp 341-343.

Verdonk JMAJ, Shim SB, Van Leeuwen P, Verstegen MWA (2005) Application of inulin type fructan in animal and pet food. Br J Nutr 93:S125-S138.

Verdonk JMAJ, Van Leeuwen P (2004) The application of inulin type fructans in diets for veal calves and broilers. In: Inulin and Oligofructose Feed Good Factors for Health and Well Being. $4^{\text {th }}$ Orafti Research Conference, Paris.

Williard MD, Simpson RP, Delles EK, Coben ND, Fossum TW, Kolp D, Reinhart G (1994) Effects of dietary supple- mentation of fructooligosaccharides on small intestinal bacterial overgrowth in dogs. Am J Vet Res 55:654-659.

Xu J, Mahowald MA, Ley RE, Lozupone CA, Hamady M, Martens EC, Henrissat B, Coutinho PM, Minx P, Latreille P, Cordum H, Van Brunt A, Kim K, Fulton RS, Fulton LA, Clifton SW, Wilson RK, Knight RD, Gorodn JI (2007) Evolution of symbiotic bacteria in the distal human intestine. PloS Bio 5:e156.

Yusrizai Y, Chen TC (2003) Effect of adding chickory fructan in feed on broiler growth performance, serum cholesterol, and intestinal length. I J Poultry Sci 2:214-219.

All the content of the journal, except where otherwise noted, is licensed under a Creative Commons License CC BY-NC. 